\title{
War, Peace, and the Size of Countries
}

\section{Citation}

Alesina, Alberto, and Enrico Spolaore. 2005. War, peace, and the size of countries. Journal of Public Economics 89(7): 1333-1354.

\section{Published Version}

http://dx.doi.org/10.1016/j.jpubeco.2003.07.013

\section{Permanent link}

http://nrs.harvard.edu/urn-3:HUL.InstRepos:4553002

\section{Terms of Use}

This article was downloaded from Harvard University's DASH repository, and is made available under the terms and conditions applicable to Other Posted Material, as set forth at http:// nrs.harvard.edu/urn-3:HUL.InstRepos:dash.current.terms-of-use\#LAA

\section{Share Your Story}

The Harvard community has made this article openly available.

Please share how this access benefits you. Submit a story.

Accessibility 

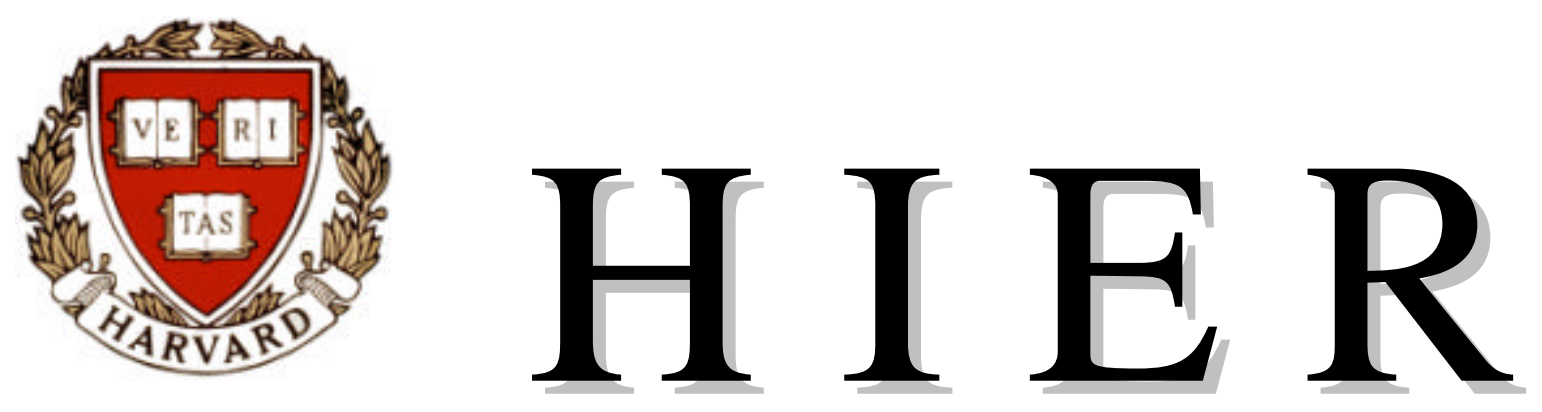

\title{
Harvard Institute of Economic Research
}

Discussion Paper Number 1937

\section{War, Peace and the Size of Countries}

\author{
By \\ Enrico Spolaore and \\ Alberto Alesina
}

\author{
November 2001 \\ Harvard University \\ Cambridge, Massachusetts
}

This paper can be downloaded without charge from the:

http://post.economics.harvard.edu/hier/2001papers/2001list.html

This paper available from the Social Science Research Network at:

http://papers.ssrn.com/abstract=293780 


\title{
War, Peace and the Size of Countries
}

\author{
Enrico Spolaore \\ Brown University \\ e-mail: Enrico_Spolaore@brown.edu \\ Alberto Alesina \\ Harvard University, NBER, and CEPR \\ e-mail: aalesina@harvard.edu
}

This draft: August 2000

\begin{abstract}
A bstract
This paper studies the relationship between international conłict and the size distribution of countries in a model in which both peaceful bargaining and non-peaceful confrontations are possible. We show how the size distribution of countries depends on the likelihood, bene..ts and costs of conłict and war. We also study the role of international law and show how better de..ned international 'property rights' may lead to country breakup and more numerous local conłicts.
\end{abstract}

\section{Introduction}

In the last decade the reduction in the probability of con $\neq$ ict between an Eastern bloc and a Western bloc has been accompanied by: 1) the breakup of several countries, leading to a sharp increase in the number of independent political units in the world ${ }^{1}$, and 2) an increase in the number of regional conficts. In 1985, close to the end of the cold war, there were 170 countries in the word (of which 34 in Europe); today there are 192 countries in the world (of which 44 in Europe). Several commentators have argued that some of the past conłicts, for instance those involving Iraq and K uwait and the following tensions, the war between Ethiopia and the newly independent E ritrea, and the renewed conficts in the Balkans, would not have exploded in the bipolar word of the East-West

\footnotetext{
${ }^{1}$ In this paper we refer to "independent political unit", "country" and "nation" interchengeably. When we present our model of country formation, we will de..ne "countries" precisely within our analytical frameweork
} 
conłict. ${ }^{2}$ A related argument concerns the size of the "peace dividend," that is, the reduction of military spending that has followed the end of the cold war. The size of the peace dividend has been less spectacular than one may have hoped, perhaps because regional instability has increased even though the East-West tension has declined.

These observations motivate the following questions: How does the possibility of international con $\neq$ ict and warfare relate to the size distribution of countries? Is it possible that a reduction in the probability of a global con $¥$ ict can be associated with more widespread local conficts? How does the "peace dividend" depend on changes in the probability of confict when the size distribution of countries is endogenous?

In this paper we provide a model where secessions, uni..cations and wars are possible, and derive implications that may help to shed some light on the above observations. This paper contributes to the economic literature on the size distribution of countries. ${ }^{3}$ W hile in our previous work we emphasized bene.ts of size emerging from economy of scale in the provision of public goods and from the size of the market, in this paper we focus on the bene.ts of size that arise form considerations of international security. In a way, we build on an old tradition of political analysis: the trade-ox between security and the ability to form a homogenous polis has concerned people at least since the times of classical Greece and Renaissance Italy. ${ }^{4}$ In a companion paper (Alesina and Spolaore, 2000) we study the relationship between conłict and number of nations in a model in which conłict occurs between randomly-matched individuals. By contrast, in this paper we focus on the formation and break-up of political jurisdictions when countries face a more general conłict-resolution technology, in which both international peaceful bargaining and non-peaceful confrontations between nations are explicitly modeled within a game-theoretical framework. In this paper the emergence and resolution of conłict is linked to the geographical distribution of regions. Such a framework allows us to analyze how some important changes in the international environment may axect the determination of political borders. In particular, we study the link between the rule of 'international law' and the incentives to form larger political unions.

Our work attempts to build a bridge between the literature on country formation and the literature on confict resolution and arms races, pioneered by Schelling (1960), Boulding (1962), Olson and Zeckhauser (1966), and Tullock

\footnotetext{
${ }^{2}$ For instance, see Hobsbawn (1994).

${ }^{3}$ Contributions include Friedman (1977), Casella and Feinstein (1990), Wei (1992), Bolton and Roland (1997), A lesina and Spolaore (1997), and Alesina, Spolaore and Wacziarg (1997). A discussion of this literature is provided in Bolton, Roland, and Spolaore (1996).

${ }^{4}$ See Dahl and Tufte (1973).
} 
$(1974 ; 1980)^{5}$ Formal and empirical analyses of the relationship between wars and domestic institutions for given country borders are provided by Gar..nkel (1994) and Hess and Orphanides (1995, 1997). The stability of empires in a model with confict is studied by Findlay (1996). Of course, the economic literature on confict and wars is only a fraction of the much larger political-science literature on these topics. For instance, some recent contributions within the ..eld of political science and international relations are discussed in B rown, Cote, Lynn-J ones and M iller (1998).

The paper is organized as follows. In Section 2 we present a model of international conłict between countries of given size and defense capabilities. In particular, we study under what conditions conłict would be resolved through peaceful bargaining or open warfare. In Section 3 we embed our model of confict into a dynamic framework in which countries and defense spending are endogenously determined in equilibrium. We show how the number and size of countries depend on the probability, bene..ts and costs of confict and war. In particular, we show how a decrease in the probability of conłict and/ or war may lead to more conłict and wars in equilibrium because of the endogenous breakup of countries. Section 4 explores an extension: the introduction of some form of international law. Section 5 concludes.

\section{Modeling international conłict}

In this section we develop a simple model of international conłict between countries of given size. That is, we assume that wars can take place only between countries that have been already formed. ${ }^{6}$ In the following sections we will embed this confict resolution in a model of endogenous country formation.

Following the economic literature on wars, we model confict as appropriative/ distributional, i.e., over the sharing of an economically valuable "pie." M ore speci..cally, we assume that international conłict may arise when international control rights over some valuable resource are not speci..ed or not enforceable. While this speci..c reason for wars is not uncommon, our model of conłict can be interpreted more generally, as discussed in A ppendix A.1.

\footnotetext{
${ }^{5} \mathrm{M}$ ore recent contributions are surveyed in various chapters in Hartley and Sandler (1995). See also Hirshleifer (1989; 1991; and 1995). A related line of research focuses on domestic conłict and insurrections - for instance, see Grossman (1991) and Grossman and K im (1995).

${ }^{6}$ Therefore, we do not model civil wars explicitly. As we will see, when we embed our model of con $¥$ ict into a model of endogenous country formation, "civil wars" will be implicitly considered as part of the costs of forming a larger, more heterogenous political unit.
} 
For simplicity, we will focus on bilateral conłicts. While multilateral con¥icts and alliances are certainly important and have been studied extensively in the literature, we abstract from them in this analysis. ${ }^{7}$ Consider two countries (country j and country j 0 . Suppose that there exists a resource $R$ on which both countries have claims, e.g., oil reserves located in international waters between the two countries, or, more generally, anything valuable to both countries and upon which international control rights are not speci..ed or not enforceable. The countries may resolve their potential conłict with war or bargaining. Wars are costly: if country $j$ goes to war, its aggregate cost is given by $c_{j}, 0$ : For simplicity, and without much loss of generality, we assume that war costs are constant across countries, i.e., $c_{j}=c_{j} 0=c, 0$.

Each country has a strategy set of two: $3 / 4=3 / 40=$ ff ight; bargaing. ${ }^{8}$ The payous are as follows. When both countries decide to ..ght, the net payous are

$$
\begin{aligned}
& u_{f f}^{j}=\frac{d_{j}}{d_{j}+d_{j} 0} R i c \\
& u_{f f}^{j 0}=\frac{d_{j 0}}{d_{j}+d_{j} 0} R i c
\end{aligned}
$$

where $d_{j}\left(d_{j 0}\right)$ is military spending in country $j\left(j 0 .{ }^{9}\right.$

This speci..cation closely follows the literature on conłict resolution, where the relative spending on defense determines the likelihood of winning, or the relative fraction of the splitting of the pie. In case of risk neutrality (which we assume) the two interpretations are identical in terms of expected utility.

If both countries choose to bargain, we adopt a Nash bargaining solution to share the pie. For the disagreement point we choose, quite naturally, the war outcome. Under these assumptions, the Nash bargaining solution implies allocations shares $\mathbb{S}_{j}^{a}$ and $1 \mathrm{i} \mathbb{\beta}_{j}^{\mathrm{q}}$, such that

$$
u_{b b}^{j}={ }_{\circledast j}^{a} R
$$

\footnotetext{
${ }^{7}$ As we will brieły discuss, one could reinterpret our concept of "political unit/country" to encompass tight alliances in which decisions over defense and conłict are completely and credibly centralized.

${ }^{8}$ For simplicty, we rule out the option of "surrender without a ..ght." Alternatively, we could allow for such a strategy and assume that it is always dominated by either ..ght or bargain.

${ }^{9} \mathrm{~T}$ his speci..cation is a special case of the more general "con¥ict resolution technology" in which country j's "probability of winning" is given by
}

$$
\frac{\tilde{A}\left(d_{j}\right)}{\bar{A}\left(d_{j}\right)+\tilde{A}\left(d_{j}\right)}
$$

See Tullock (1980), Hirshleifer (1989, 1995), and Gar..nkel (1994). 


$$
\left.u_{b b}^{j 0}=\left(\begin{array}{ll}
j_{i} & \mathbb{B}
\end{array}\right)^{\circledR}\right) R
$$

where

$$
\begin{aligned}
& \left.\Theta_{j}^{a}=\arg \max [\Theta i) i \frac{d_{j}}{d_{j}+d_{j 0}} R+c\right]\left[(1 ; \quad \Theta) R i \frac{d_{j 0}}{d_{j}+d_{j} 0} R+c\right]
\end{aligned}
$$

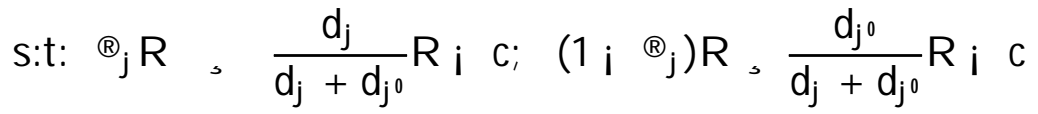

which gives ${ }^{10}$

$$
\mathbb{R}_{j}^{\alpha}=\frac{d_{j}}{d_{j}+d_{j} 0}
$$

For $c=0$, the two countries obtain the same net payous no matter whether they engage in open warfare or in Nash bargaining. For any $c>0$, the bargaining outcome Pareto dominates the ..ght outcome. However, (bargain, bargain) may not be an equilibrium.

In order to illustrate this point we need to specify the payous for the (bargain, ..ght) and the (..ght, bargain) outcomes. When country j chooses to ..ght while country $\mathrm{j}$ Ochooses to bargain we denote their respective payous as

$$
\begin{aligned}
& u_{f b}^{j}=\frac{d_{j}}{d_{j}+d_{j} 0} R+E_{j} i c \\
& u_{f b}^{j 0}=\frac{d_{j} 0}{d_{j}+d_{j} 0} R ; e_{j} 0 i c
\end{aligned}
$$

The idea is that, while the decision to ..ght by at least one country will always trigger an open confict in which both countries will eventually ..ght, the ..rst country to mobilize for war may enjoy a "..rst-striker's advantage". $E_{j}, 0$ denotes this "..rst striker's advantage" ("surprise gain"): it measures the additional gain that country $\mathrm{j}$ can obtain by engaging in open warfare while country $\mathrm{j}{ }^{0}$ proposes to bargain. ${ }^{11}$ Conversely, $e_{j} 0$, 0 denotes country $\mathrm{j}^{0}$ "surprise loss," i.e.,

\footnotetext{
${ }^{10}$ It is immediate to see that, when the costs associated with open conłict are asymmetric, countries that are "weak" in terms of military strenght but face low "war costs" may obtain more at the bargaining table than countries with bigger muscles but also larger war costs. Speci..cally, for $c_{j} \in c_{j}$, we have

$$
\mathbb{R}^{\mathrm{k}}=\frac{\mathrm{d}_{\mathrm{j}}}{\mathrm{d}_{\mathrm{j}}+\mathrm{d}_{\mathrm{j} 0}}+\frac{\mathrm{C}_{\mathrm{j} 0 \mathrm{i} \mathrm{c}_{j}}}{2 R}
$$

provided that both countries obtain through bargaining at least as much as they would through open confict. In this paper we will not pursue this immediate extension and maintain the simplifying assumption that war costs are symmetric across countries.

${ }^{11}$ On these issues a classical discussion is Shelling (1966). See also Van Evera (1998).
} 
the loss that country j Owould suxer should propose to bargain while the other country attacks.

One can think of $E_{i}$ as the sum of three components: 1) the bene.ts stemming from a higher probability of winning because of a surprise attack; 2) lower war costs (hence, $E_{i}$ may be a function of $c$ ); 3 ) other economic and political bene.ts . A nalogously, $e_{i}$ includes the costs due to 1 ) a lower probability of winning when a country is taken "by surprise"; 2) higher war damage; 3) other economic and political costs. ${ }^{12}$ A nalogously, if country $j$ decides to bargain while country $\mathrm{j}^{0}$ "strikes," their respective payous are:

$$
\begin{gathered}
u_{b f}^{j}=\frac{d_{j}}{d_{j}+d_{j} 0} R ; e_{j} i c \\
u_{b f}^{j 0}=\frac{d_{j 0}}{d_{j}+d_{j 0}} R+E_{j 0} i c
\end{gathered}
$$

Clearly, if $E_{j}=E_{j 0}=e_{j}=e_{j 0}=c=0$; all strategies are payox-equivalent.

It is immediate to verify that:

\section{Fact 1}

The strategy pro..le (..ght, ..ght), is always a Nash equilibrium. ${ }^{13}$ It is the unique Nash equilibrium if and only if $\operatorname{maxf}_{j} ; E_{j} \circ g>c, 0$. The strategy pro..le (bargain, bargain), is also a Nash equilibrium if and only if $\operatorname{maxf}_{\mathrm{j}}$; $E_{j} \circ \mathrm{g}$ C.

That is, open conłict is the only Nash equilibrium if and only if the advantage of a surprise strike more than ousets the costs of open warfare for at least one country. Note that, in equilibrium, there will be no "surprise attack," and, for any $c>0$, both countries will be worse ox than they would be had they bargained (the game is a standard Prisoner's dilemma). A high enough "temptation" to strike induces open confict as the unique suboptimal equilibrium.

On the other hand, bargaining can be sustained as an equilibrium if and only if the costs of open confict are higher than the temptation to strike for both countries. When $\operatorname{maxf} E_{j} ; E_{j} \circ g \quad C ;$ (..ght, ..ght) is still a Nash equilibrium. However, for any C > 0; (bargain, bargain) Pareto dominates (..ght, ..ght): $:^{14}$ (bargain, bargain) also dominates the mixed equilibrium that exists for $\operatorname{maxf}_{j} ; E_{j} \circ g$ C:

\footnotetext{
${ }^{12}$ In general, both $E_{i}$ and $e_{i}$ may be modeled as function of $R$ and/ or c: Our results would not be axected by those speci...cations.

${ }^{13} W$ hen $\operatorname{maxf} E_{j} ; E_{j} \circ g \quad C ;(. . g h t, . . g h t)$ is not an equilibrium in weakly dominated strategies as long as $e_{\mathrm{f}}>0$ and $\mathrm{e}_{0}>0$.

${ }^{14} \mathrm{~N}$ ote that, for maxf $E_{j} ; E_{j 0 g} \quad C$; our game is a general case of the "stag hunt" game cited in Harsanyi and Selten (1988) and Farrell (1988), and discussed in Aumann (1990). See also Fudenberg and Tirole (1991, p. 20-21). For an application to international relations in a dixerent but related context see J ervis (1978).
} 
In the rest of the analysis we will abstract from mixed-strategy equilibria. Our results will not be axected.

What is the most reasonable prediction of how this game will be played? Clearly, if the ..rst-striker's advantage is high enough, the only Nash equilibrium is given by "both countries ..ght," and open warfare is the only noncooperative equilibrium outcome in a one-shot game. When the .rst striker's advantage is lower than direct war costs, open warfare and peaceful bargaining are both Nash equilibria. So is a mixed equilibrium in which each country ..ghts and bargains with positive probabilities. However, this multiplicity of equilibria is reduced to a unique equilibrium when the re. nement of coalition-proofness is introduced: only the Pareto-dominant (bargain, bargain) equilibrium is robust to coordinated deviations. The following holds:

\section{Fact 2}

If $\operatorname{maxf} E_{j} ; E_{j} \circ g>c>0$; the strategy pro..le (..ght, ..ght) is the unique Coalition-Proof Nash equilibrium. If $\operatorname{maxfE}_{j} ; E_{j} \circ g \quad c>0$; the strategy pro..le (bargain, bargain), is the unique Coalition-P roof Nash equilibrium. ${ }^{15}$

In other words, when (bargain, bargain) is a Nash equilibrium, two countries that are able to "communicate" could jointly move away from the "bad equilibrium" (..ght, ...ght) and "coordinate" to the "good equilibrium" (bargain, bargain): As the good equilibrium is Nash, it can be supported without any speci... commitment technology. ${ }^{16}$

In summary, using the coalition-proof re..nement, this game has an unambiguous outcome: war if the ..rst striker's advantage is higher than war costs in at least one country, peaceful bargaining otherwise. As we discuss below, the concept of coalition-proof equilibrium is a natural choice when we embed our model of conłict into a model of endogenous country formation and defense spending. While we will focus upon Coalition-proof Nash as our equilibrium concept, we will also compare the predictions of coalition-proof equilibria with the predictions of alternative equilibrium concepts (Strong $N$ ash and standard subgame perfect equilibrium).

\footnotetext{
${ }^{15}$ For a formal de. nition of coalition-proof $\mathrm{N}$ ash equilibrium see B ernheim, Peleg and Whinston (1987). For every two-player game, the set of coalition-proof Nash equilibria coincides with the set of Nash equilibria that are not Pareto dominated by any other Nash equilibrium.

${ }^{16} \mathrm{~T}$ he logic behind the concept of coalition-proof $\mathrm{N}$ ash equilibrium appears compelling when two sovereign countries have the means and the opportunity to engage in preplay communication and make it known to each other that they intend to bargain rather than to ..ght, if that is to their mutual advantage, and if it is a Nash equilibrium. However, communication may not be suф cient. As we will brieły discuss below, in some circumstances lack of "trust" may prevent such coordination (A umann, 1990)
} 


\section{Endogenous countries}

Now, we use our model of international con $¥$ ict within a framework in which both defense spending and country borders are endogenous.

\subsection{The model}

The "world" is a set of regions, each inhabited by a (discrete) number of homogeneous individuals. For simplicity, we normalize the number of individuals in each region to one. Appendix A.3 shows that our results do not change if we allow for the number of individuals in each region to be equal to any strictly positive integer. Each region borders two others. We need a minimum of four regions to make our points; in fact, four is the minimum even number of regions such that uni..cation does not necessarily imply total elimination of international conłict. Two regions are located in the "West" (region W 1 and region W 2 ) and two are located in the "East" (region E1 and region E2). Western regions are contiguous and so are Eastern regions. To ...x ideas, we assume that the four regions are distributed as points on a circle (..gure 1). The segment connecting a pair of regions measures the portion of world surface to which both regions have access (i.e., seas between them). Regions cannot split by assumption, but regions can merge to form countries composed of more than one region. Therefore, if two regions merge the portion of the world which is in between them becomes part of the uni..ed country.

As we will make clear below, in our model a "country" is de..ned as an independent political unit in which a) defense is completely and credibly centralized; b) a uni..ed government takes decisions over bargaining and war strategies; and c) the "net returns" from conłict are distributed across its citizens. ${ }^{17}$

Consistently with the literature on country formation, we assume that the formation of a larger, less homogeneous country implies some "heterogeneity" costs. ${ }^{18}$ Those costs can have multiple sources. They may be related to heterogenous preferences over public policies, coordination costs, monitoring costs. In some cases, part of these costs may come from the expected losses associated with the possibility of a civil war, or other major domestic upheavals due to high heterogeneity within a country. For simplicity we assume that the heterogeneity costs of forming a country including both an Eastern and a Western region are prohibitive. By contrast, if E1 and E2 form a uni..ed country, each individual in

\footnotetext{
${ }^{17}$ Therefore, in principle, tight supranational alliances could be classi..ed as "countries" in our framework insofar as they satisfy our de. nition. In practice, states that join actual military alliances tend to retain sovereignity on most matters sub a)-c).

${ }^{18}$ In particular, see A lesina, Perotti and Spolaore (1995), B olton, R oland and Spolaore (1996), A lesina and Spolaore (1997), and A lesina, Spolaore and Wacziarg (2000).
} 
each region will bear a cost $0 \quad h_{e}<1$. A nalogously, if $W 1$ and $W 2$ form a uni..ed country, each individual in each region will bear a cost $h_{w}$ : Without loss of generality, we impose $0 \quad h_{w} \quad h_{e}$ :

We also assume that heterogeneity costs are the same for every member of a country, namely they do not depend on the location of each individual within the country. ${ }^{19}$

The utility function for each individual $i$ is

$$
u_{i}=y_{i} \text { i } t_{i}+r_{i} i \quad h_{i}
$$

where $y_{i}$ is the individual's income, $t_{i}$ measures the individual's taxes, $r_{i}$ measures the individual's net returns from "conłict resolution," as speci..ed below (including direct "war costs" and "surprise gains or losses," if any), \# is a binary index which takes value 0 if the individual lives in an independent region and value 1 otherwise. Finally, we have $h_{i}=h_{w}$ if the individual lives in a Western region, whilst $h_{i}=h_{e}$ if the individual lives in an Eastern region.

B orders, taxes and returns from conłict resolution are endogenously determined as equilibrium outcomes of an extensive game that we will specify below.

Let $d_{j}$ denote defense in country $j:$ O ne unit of defense costs one unit of income and is ..nanced through a proportional income tax. The tax rate is denoted with $i_{j}$ : Let $S_{j}$ denote the set of individuals in country $j$ : Then we have that

$$
i_{j}{ }_{i 2 s_{j}}^{x} y_{i}=d_{j}
$$

For simplicity, we will abstract from ex-ante income inequality, and assume that each individual in the world has the same income (bef ore taxes and bef ore confict resolution): $y_{i}=y$. Therefore, the above budget constraint equation simpli..es to

$$
i_{j} s_{j} y=d_{j}
$$

where $s_{j}{ }^{\prime} j S_{j} j$ is the number of individuals in country $j::^{20}$

Defense is used to set potential conłicts with neighboring countries. Consistently with the model presented in the previous section, we consider a simple

\footnotetext{
${ }^{19}$ T his assumption is simpler than the setup of Alesina and Spolaore $(1997,2000)$ where the heterogeneity costs depended on individuals' location on an ideological and/or geographical line.

${ }^{20} \mathrm{~S}_{\mathrm{j}}$ is either 1 or 2 . For a more general speci..cation see A ppendix A.3.
} 
"distributional conłict": somewhere on the circle there exits a valuable natural resource, which will be discovered with probability $1 / 4$ after political borders and defense allocations have been decided.. This order of moves underlies a "timing" that we regard as realistic. That is, we assume that borders are set before defense spending is decided, and defense must be in place before actual confict arises. This timing makes sense within a dynamic framework by noting that: a) border changes are more costly than changes in defense spending, and, in fact, are observed more rarely; and b) building defense takes time.

Finally, we also assume that, when borders and defense are decided, individuals do not know whether, should a confict arise, it will be resolved through bargaining or through war. It seems appropriate to assume that the precise features of potential conłicts and their resolution are uncertain when borders and defense investments are decided. The alternative would be to assume that every time a secession or uni..cation is decided, and defense spending levels are chosen, there is certainty about the incentives for armed conłicts and/ or peaceful bargaining in future conłicts.

Speci..cally, we assume a three-stage game with the following structure:

In the ..rst stage, the individual in each region decides on whether its region should form a uni..ed country with the neighboring region (E 1 with E 2 and W 1 with W 2) or should form an independent country. ${ }^{21}$ Borders are decided accordingly; namely a country is formed if and only if citizens in both regions contemplating to form a country agree. In other words, in stage 1 each region can choose from an action set of two. The action space of each player in each region is: \{decide for union, decide for independence\}. If at least one Eastern (Western) region prefers independence, the two Eastern (Western) regions will form two independent countries. In other words, a uni..ed East will emerge if and only if both E1 and E2 decide for uni..cation. A nalogously, a uni..ed west will emerge if and only if both W 1 and W 2 vote for uni..cation.

In stage two (i.e., after borders have been decided), a government is elected in each country. A fter the election the government acts as a uni..ed "agent," namely it is the unique player for each country in the following stages of the game. In countries formed by one region, the government's objective function is identical to citizens' utility. ${ }^{22}$ In countries formed by two regions, the government's objective

\footnotetext{
${ }^{21}$ By assuming one individual in each region (or, more generally, $M$ individuals with identical preferences, as studied in A ppendix A.3), we can abstract from issues of preference aggregation within regions. In particular, any voting rule would deliver the same decision within each region. Therefore, we will refer to a "region" as an individual player in the rest of the analysis.

${ }^{22}$ In other words, we assume that voters are able to elect an ideal "agent" as their government. We abstract from issues such as the ability of the government to extract rents from its own citizens. For a general discussion of alternative ways of modeling governments, see Grossman (2000).
} 
is given by a weighted average of the utilities of the citizens in the two regions. The underlying idea is that the political process will rełect the relative political weights of the two regions. As we assume that the two regions have the same population size and the same income per capita, it is natural to assume that their relative weights are identical.

In each countpy $j$, the government chooses the level of defense spending $d_{j}$, where $0 \quad d_{j} \quad{ }_{i 2} s_{i} y_{i}$. Defense spending $d_{j}$ can take any real value between zero and the maximum amount of resources available in the country. ${ }^{23} \mathrm{As}$ we will see, preferences over defense are identical across individuals within each country. Therefore, our assumption that defense is chosen by utility-maximizing governments is equivalent to having defense chosen through direct voting within each country. However, it seems more realistic to assume that decisions over defense and, in the third stage, war or bargain, are taken by centralized governments rather than through direct-democracy referenda.

In stage three, after defense is decided, uncertainty is resolved, namely the "location" of R and the value of $\mathrm{E}$ are revealed. In particular, we assume that, with probability $1 / 4$ a "pie" of size $R$ is found on a point along the circle. For simplicity, and without much loss of generality, we assume that the probability that $R$ will "located" between any two given regions is $\frac{1 / 4,24}{4}:$ Moreover, we assume that, with probability $1 / 2$ the speci..c confict at hand implies a ..rst striker's advantage $\mathrm{E}$ larger than $\mathrm{C}$, while, with probability 1 i $1 / 7$ we have $E<c$. In our model, the dixerence $\mathrm{E}$ i $\mathrm{c}$ captures the incentives to unilaterally start a war. Our assumption stems from the view that those incentives will depend on technological, economic and political factors known only when the location and the nature of the conłict are revealed. ${ }^{25}$ As mentioned above, the assumption that uncertainty is resolved at the beginning of stage three refects the plausible view that building defense takes time, and by the time the existence and nature of speci..c conłicts are known, countries must have already invested in their own defense. Depending on the location of the resource, at most two countries may lay a claim on it. ${ }^{26}$ The resource $\mathrm{R}$ is allocated through bargaining or conłict. In stage three, each government involved in confict chooses ..ght or bargain in

\footnotetext{
${ }^{23}$ For simplicity, we assume that the constraint $d_{j} \quad P \quad{ }_{i 2} s_{j} y_{i}$ is never binding in equilibrium.

${ }^{24}$ One could easily extend the model to allow for dixerent ex-ante probabilities of conłict between pairs of regions.

${ }^{25}$ For simplicty, we do not model those factors explicitly. In a dixerent framework, Hess and Orphanides $(1995,1997)$ explore a governmnt's incentives to start an "avoidable war" as a function of economic and political conditions.

${ }^{26} \mathrm{~A} s$ we al ready mentioned, to keep the analysis simple we implicitly assume that geography and/ or technology prevent third parties from getting involved in those bilateral conłicts. In other words, we rule out the possibility of transfer and/ or commitment technologies that could allow a third country to promise outside help to a country in confict in exchange for a share of the spoils.
} 
order to maximize the utility of its citizens as speci..ed above. At this terminal stage, each government's objective is equivalent to the maximization of "con $¥$ ict returns," which we will specify consistently with our analysis in Section 2 . In particular, confict returns to country j facing country j Oare:

$$
\frac{d_{j}}{d_{j}+d_{j 0}} R
$$

when both countries bargain;

$$
\frac{d_{j}}{d_{j}+d_{j} 0} R i c
$$

when both countries ..ght;

$$
\frac{d_{j}}{d_{j}+d_{j 0}} R+E j c
$$

when country j chooses to ..ght a bargaining opponent;

$$
\frac{d_{j}}{d_{j}+d_{j 0}} R \text { i e i c }
$$

when country j proposes bargaining but country j Ochooses to ..ght. ${ }^{27}$

In summary, we have an extensive-form game with eleven players (the four regions, the six possible governments, and nature). ${ }^{28}$ In stage one, the four regions move. The regions endogenously determine which governments are going to move in stage two. Depending on the regions' combinations of strategies, there are sixteen possible nodes, that are associated with four possible con..gurations of the world (four independent countries, a uni..ed East and two independent countries in the West, a uni..ed West and two independent countries in the East, two uni..ed countries). In stage two up to a maximum of four governments move. As they can choose defense spending along a continuum, their actions lead to an in..nite number of possible subgames in stage 3 . At the beginning of stage three, "nature" moves and chooses whether a potential conłict will take place, where, and whether $\mathrm{E}$ is larger or smaller than $\mathrm{c}$. Then, at most two governments move. Depending on the endogenous choice of political borders in stage one, and on the moves by governments in stage three, actual conficts and possibly wars will be observed. Figure 2 summarizes the timing of the game.

\footnotetext{
${ }^{27}$ W ithout loss of generality, we assume that the "surprise loss" is the same across countries.

${ }^{28}$ In A ppendix A.3 we consider the more general case in which $M, 1$ individuals live in each region. Then, the extensive-form game has $4 M+6+1$ players.
} 


\subsection{Equilibria}

In our analysis we focus upon Coalition-Proof Nash equilibria. More precisely, as we have an extensive-form game, we will use the extensive-form re..nement of the concept, Perfectly Coalition-P roof Nash equilibrium, as de..ned in Bernheim, Peleg and Whinston (1987).

When looking at coalition-proof equilibria, one needs to consider deviations by "coalitions" of players. ${ }^{29}$ It is important to note that the concept of "coalition," in this context, should not be confused with the concepts of "region," "country," or "government." In this paper, the word "coalition" will be used consistently with the technical de.nition of coalition-proof equilibria, i.e., as any subset of players. Therefore, we refer to "coalitions of governments" in stage two and three, and "coalitions of regions" in stage one, simply as subsets of players that may jointly deviate from any proposed equilibrium. In particular, note that a "coalition of regions" is just a subset of players, while a "country" formed by one or two regions is the outcome of a strategy pro..le.

O ur game has a unique Perfectly Coalition-P roof Nash equilibrium, which can be derived as follows. ${ }^{30}$

First, we restrict all possible pairs of governments to play Pareto undominated equilibria in all two-player subgames of the terminal stage. In other words, governments will play "bargain" if $E \quad c$ and "..ght" if $E>C$.

We will then consider the subgames consisting of the terminal two-stage games. We will show that, given the payous supported by stage-three equilibria, for each possible con..guration of countries, there exists a unique Nash equilibrium in which each government chooses a speci..c level of defense. We will show that the unique Nash equilibrium in the terminal two-stage subgame is coalitionproof. We will then consider the game played by the four regions in the ..rst stage. In the ..rst stage, each strategy pro..le implies a given con..guration of the

\footnotetext{
${ }^{29} \mathrm{M}$ ore speci..cally, the de..nition of coalition-proof equilibrium proceeds by induction on the size of all possible coalitions of players. As in the standard de..nition of Nash equilibrium, one requires that no "one-player coalition" can improve its situation by deviating. Then, the de..nition requires that no "two-player coalition" can improve the situation of its members by deviating, but the only joint deviations that are allowed are those from which no member of the deviating coalition has an incentive to deviate individually. In other words, all two-player deviations must be Nash equilibria of the two-player game induced by holding the strategies of all the other players ..xed. Then, for games with more than two players, three-player coalitions are considered, etc., all the way to the "grand coalition" of all players.

${ }^{30} \mathrm{~A}$ fter we derive the coalition-proof equilibrium for this game, we will discuss why we believe that the concept of coalition-proof equilibrium is the natural equilibrium concept within our context.
} 
world, to which unique equilibrium payo vectors are associated. Each region will play coalition-proof equilibrium strategies. We will show that those equilibrium strategies characterize a unique equilibrium con..guration of the world for given values of the parameters.

In summary, for a given vector of parameters $\left(h_{e} ; h_{w} ; 1 / 4 R, 1 / 3 c\right)$ we can ..nd unique values for a) the equilibrium number and size distribution of countries; b) the equilibrium distribution of defense levels per capita across countries, and c) the equilibrium probabilities of international conłict and war. Note that $1 / 4$ measures the probability of a "potential" confict, and $1 / 2$ the probability that, should a confict arise, it will be solved through war. The probability of observing an actual international confict, and the probability than an actual war will indeed occur, are both endogenous variables within our model, since they depend on the size distribution of countries.

\subsubsection{Equilibrium defense and expected returns from con¥ict}

We will now derive the equilibrium levels of defense spending and the equilibrium returns from conłict for each possible con..guration of countries.

\section{Lemma 1}

Equilibrium defense spending per capita in country $i$ is given by

$$
d_{i}=\frac{1 / R}{8 s_{i}}
$$

Proof: in Appendix.

This result shows that, by forming a larger union, equilibrium defense per capita is reduced. By de..ning "expected con $¥ c i t$ returns" for each country as its expected share of $\mathrm{R}$ minus expected war costs, we have the following

\section{Lemma 2}

For every con..guration of countries and for every country of size $s_{i}$, expected conłict returns per capita in equilibrium are given by

$$
\frac{1 / R}{4} i \frac{1 / 4^{1 / \varepsilon}}{2} \frac{s_{i}}{s^{2}}
$$

Thus, in equilibrium, when wars are either impossible $(1 / 2=0)$ or costless $(c=0)$, individuals within each country will obtain the same expected returns 
from conłict, irrespectively of whether they live in a large country or in a small country. However, because of Lemma 1, individuals living in a large country enjoy a bene..t from size: their expected return comes "cheaper," i.e., at a lower cost in terms of defense per capita. In other words, a larger size brings about net economies of scale in defense. In addition, when wars are possible $(1 / 2>0)$ and costly ( $c>0$ ), a larger size reduces expected war costs.

\subsubsection{Equilibrium number and size of countries}

The above analysis of equilibrium defense spending and equilibrium expected returns from conłict point to a scale advantage: larger countries can exploit economies of scale in defense. However, these bene.ts have to be weighted against the higher heterogeneity costs. We are now ready to study under what conditions the bene..ts from size associated with conł ict resolution are larger or smaller than the heterogeneity costs.

\section{Lemma 3}

Given heterogeneity cost $h_{k}(k=w ; e)$, and given the equilibrium payoxs associated with all possible con..gurations of countries (i.e., with all terminal twostage subgames), individuals will (strictly) prefer to live in a two-region country rather than in an independent region if and only if

$$
\frac{1 / 4}{4}\left(\frac{R}{4}+1 / \sqrt{2}\right)>h_{k}
$$

Proof: in Appendix

The term $\frac{1 / 4}{4}\left(\frac{R}{4}+1 / \varepsilon\right)$ can be interpreted as "net con $\neq i c t$ bene..ts from uni..cation," i.e., as those bene..ts stemming from lower defense spending per capita and lower expected war costs in a larger country. Lemma 3 states the intuitive result that uni..cation will be more likely to be preferred to independence the higher the probability and/ or relevance of a potential con $\ddagger$ ict and the higher the probability that the confict leads to open warfare, and the lower the heterogeneity costs associated with uni..cation.

\section{Proposition 1} have:

For all $0<h_{w} \quad h_{e} ; 1 / 4,0, c, 0$ and $0 \quad 1 / 2 \quad 1$; in equilibrium we will

1) Four independent regions ( $N=4$ ) if and only if

$$
\frac{1 / 4}{4}\left(\frac{R}{4}+1 / \varepsilon\right) \quad h_{w}:
$$


2) A uni..ed West and two independent countries in the East ( $N=3$ ) if and only if

$$
h_{w}<\frac{1 / 4}{4}\left(\frac{R}{4}+1 / \mathbb{L}\right) \quad h_{e}:
$$

3) A uni..ed West and a uni..ed East $(N=2)$ if and only if

$$
\frac{1 / 4}{4}\left(\frac{R}{4}+1 / \sqrt{2}\right)>h_{e}:
$$

Proof: in A ppendix

This proposition states the intuitive result that, when the "conłict bene..ts" from uni..cation are lower than the lowest heterogeneity costs (i.e., $\frac{1 / 4}{4}\left(\frac{R}{4}+1 / 2\right)<$ $\left.h_{w}\right)$, independence is the equilibrium strategy in each region. If $h_{w}<\frac{1 / 4}{4}\left(\frac{R}{4}+\right.$ $1 /[)<h_{e}$; the bene.ts from uni..cation are high enough to compensate Western regions for their (lower) heterogeneity costs, but are too small to make uni..cation worthwhile in the East, where heterogeneity costs are assumed to be higher. If $\frac{1 / 4}{4}\left(\frac{R}{4}+1 / \varepsilon\right)>h_{e} ;$ uni..cation is the equilibrium strategy everywhere.

\subsection{Discussion}

Why should we focus on coalition-proof equilibria rather than some other equally plausible notion of equilibrium? We believe that the concept of coalition-proof equilibria provides a natural and useful prediction of how the game should be played at each stage. Let's move backwards:

-) In stage three, the coalition-proof re.nement allows the natural selection of a unique equilibrium when multiple $\mathrm{Nash}$ equilibria are possible. As long as governments can freely communicate, it seems reasonable to predict that the equilibrium outcome should be given by the unique coalition-proof equilibrium. Such an equilibrium will imply open warfare when that is the only Nash equilibrium (a prisoner's dilemma situation), but peaceful bargaining when bargaining itself is a Nash equilibrium.

What about using a stronger concept, such as A umann's (1959) Strong Nash equilibrium? In contrast to coalition-proof equilibrium, deviations by coalitions in Strong Nash equilibria do not need to be "credible" (in particular, they do not need to be Nash equilibria for the deviating coalition). Hence Strong Nash equilibria, unlike coalition-proof equilibria, must always be Pareto ed cient (otherwise, the grand coalition would deviate). When peaceful bargaining is the coalition-proof equilibrium, it is also Strong Nash. However, when war is the 
coalition-proof equilibrium outcome, it is not a Strong Nash equilibrium. In our model, for $\mathrm{c}>0$, war is not Pareto eф cient: both governments would deviate and move to bargain. However, when peaceful bargaining is not a Nash equilibrium, such a deviation cannot be enforced in the absence of some speci..c commitment technology. As a result, when (..ght, ...ght) is the unique coalition-proof Nash equilibrium in the last-stage subgame, the game has no Strong $N$ ash equilibrium. In this context, as it is often the case, the concept of Strong Nash equilibrium turns out to be "too strong." 31

-) In stage two, by focusing on coalition-proof equilibria we can consider the possibility that coalitions of governments, while remaining fully independent, jointly "coordinate" their defense spending. ${ }^{32} \mathrm{As}$ it is reasonable to require when considering agreements among sovereign states, in the absence of any external commitment technology, any "coordination" must be sustainable as a Nash equilibrium for those states.

A s we have seen, a standard subgame perfect $N$ ash equilibrium is suф cient to identify a unique level of defense spending for each country: there are no multiple equilibria in defense spending. In other words, for every proper subgame consisting of the terminal two-stages games, any subgame perfect equilibrium will identify a unique vector of defense spending. That vector is also the equilibrium defense spending that is observed in the unique perfectly coalition-proof equilibrium. In that respect, the re.nement of coalition-proofness does not play a role as an equilibrium selection criterion when defense spending is considered. However, requiring coalition-proofness has other important bene.ts. Since sovereign governments are able to communicate, a Nash equilibrium that were not robust to "credible" joint deviations should be seen with suspicion. By making sure than any subset of governments has no joint incentive to deviate from the proposed equilibrium, we can ensure that our equilibrium is robust to any self-enforcing international arms treaty among any possible subset of countries. ${ }^{33}$

A gain, the comparison with the prediction of Strong Nash equilibria is instructive. We will show that there exists a unique coalition-proof equilibrium with a positive level of defense in each country. By contrast, one can show that

\footnotetext{
${ }^{31}$ Bernheim, Peleg, and Whinston (1987) introduced the concept of coalition-proof equilibrium as a weakening of the concept of Strong Nash, which they explicitly viewed as "too strong." A nalogously, the extensive-form notion of "strong perfect equilibria" proposed by Rubinstein (1980) would be "too strong" in our context.

${ }^{32}$ Of course, "coordination" in the level of defense spending would not prevent any government to use it noncooperatively to its exclusive advantage should an actual conłict arise. In any case, within our model, no "coordination" will arise in the coalition-proof equilibrium.

${ }^{33}$ In other words, only those "arm treaties" that rely on some additional commitment technology can improve upon the unique Nash equilibrium. In this paper, we assume that those commitment technologies do not exist: agreements among sovereign states must be $\mathrm{N}$ ash.
} 
there exists no Strong Nash equilibrium level of defense. For any positive level of defense, a proportional reduction in the level of defense across countries is always Pareto improving. In fact, Pareto el ciency requires that each country should spend zero on defense (defense is pure waste from a social perspective). However, a world in which each country invests zero in its defense is not a Nash equilibrium. In such a world, each individual government has an incentive to invest in a positive amount of defense and obtain certain victory should a conłict arise. Consequently, no Strong Nash equilibrium exists.

-) Finally, in stage one, we consider possible deviations by subsets of regions. The use of coalition-proofness is suф cient to ensure that, in equilibrium, regions will play a unique equilibrium. ${ }^{34}$ More importantly, the requirement of coalition-proof ensures that equilibria are robust to (self-enforcing) joint deviations by voters who belong to dixerent regions. Conceptually, this requirement is crucial when dealing with endogenous border formation, as any con..guration of countries should be robust not only to unilateral deviations by individual regions, but also to coordinated deviations by dixerent regions. In other words, a natural equilibrium criterion when considering endogenous borders should exclude outcomes in which a subset of regions would be willing to deviate, and form an alternative set of borders, from which no further deviation by the deviating regions would occur.

W hile we have chosen to focus on coalition-proof equilibria, we are ready to entertain the possibility that, in some context, a broader notion of equilibrium could be usefully employed. For instance, in some historical circumstances, communication between governments in con $¥$ ict could be extremely diф cult, and/ or mutual "trust" could be low ${ }^{35}$. In those cases, countries deciding over uni..cation or independence may reasonably have pessimistic expectations over the outcome of conłict, and, for instance, expect that conłict will be solved through ..ght, no matter whether $\mathrm{E}$ is larger or smaller than $\mathrm{C}$. Pessimistic expectations over

\footnotetext{
${ }^{34}$ W hile there exist multiple Nash equilibria, they can be eliminated by ruling out equilibria in weakly dominated strategies. If a region in the $E$ ast (West) votes for independence, the other region in the East (West) obtains the same utility no matter whether it votes for independence or uni..cation. As a result, independence is always a Nash equilibrium. However, if uni..cation is strictly better than independence for each region, deciding for independence is a weakly dominated strategy. Obviously, uni..cation is the unique coalition-proof equilibrium when uni..cation is preferred to independence in both regions.

${ }^{35}$ See A umann (1990) for a critical view of the notion that preplay communication is su c cient to ensure the "self-enforceability" of any agreement to play the Pareto-dominant equilibrium. In our game, each player has an incentive to convince the other to bargain no matter whether he himself plans to bargain or ...ght. Now, consider a mistrustful player who would play the Pareto-dominated but "risk-dominant" strategy "..ght" in the absence of communication. He may see no reason to change his mind if informed that the other player suggests to bargain. Therefore, preplay communication betwen governments may not be enough: some minimum amount of "international trust" may be needed in order to sustain "bargain" as an equilibrium.
} 
the ability of governments in conłict to "coordinate" on the "good" bargaining outcome may sustain an alternative equilibrium, that is, a subgame perfect but not coalition-proof equilibrium characterized as follows:

For all $0<h_{\mathrm{w}} \quad h_{e} ; 1 / 4,0, c, 0$ and $0 \quad 1 / 2 \quad 1$; there exists a "pessimistic" subgame perfect equilibrium (which is not coalition-proof), such that we will have

1) Four independent regions $(N=4)$ for

$$
\frac{1 / 4}{4}\left(\frac{R}{4}+c\right) \quad h_{w}:
$$

2) A uni..ed W est and two independent countries in the East ( $N=3)$ if and only if

$$
\mathrm{h}_{\mathrm{w}}<\frac{1 / 4}{4}\left(\frac{\mathrm{R}}{4}+\mathrm{c}\right) \quad \mathrm{h}_{\mathrm{e}}:
$$

3) A uni..ed West and a uni..ed East $(\mathrm{N}=2)$ if and only if

$$
\frac{1 / 4}{4}\left(\frac{R}{4}+c\right)>h_{e}:
$$

In other words, pessimistic beliefs over confict resolution may induce the formation of larger countries (i.e., a size distribution of countries that would be consistent with coalition-proof equilibria only if $1 / 2=1$ ). Optimistically, we see our equilibrium selection based on the expectation of coordination as more realistic in the modern world. However, we do not rule out a priori that alternative" pessimistic" equilibria may have been observed historically.

\subsection{Comparative statics}

We will now return to our equilibrium concept, as characterized in Proposition 1 , and study the implied comparative statics for dixerent values of the fundamental parameters. Proposition 1 states that the equilibrium number and size of countries will endogenously depend on the relationship between probability of a potential conłict $(1 / 4)$, importance of the confict in utility's terms $(R)$, and heterogeneity costs $\left(h_{e}\right.$ and $\left.h_{w}\right)$. For given heterogeneity costs, a high $1 / 4$ and/ or a high $\mathrm{R}$ tend to be associated with larger countries, while a low $1 / 4$ and/ or a low $\mathrm{R}$ tend to be associated with more numerous, smaller countries.

Moreover, Proposition 1 shows that the number of countries depends positively on the probability that con $¥$ ict will be resolved through military confrontation ( $1 / 2$ times the direct costs of military confrontation (c). A more "bellicose" 
world implies larger countries, while a reduction in the probability of war and/ or its costs induces country break up.

Note that the probability of observing an actual international conłict depends not only on the probability that a potential confict arises $(1 / 4)$, but also on the number of countries, which depends endogenously on $1 / 4$ This endogenous link may generate a paradoxical result: a lower probability of potential conłict may be associated with a higher probability of actually observing an international confict in equilibrium.

Let $\hat{A}$ denote the probability of an international conłict. By de.nition, it will be given by

$$
\hat{\mathrm{A}}=\frac{1 / \mathrm{N}}{4}
$$

By using our Proposition, we can immediately derive the following

\section{Corollary 1}

For any $h_{w} \quad h_{e}$ such that $1 / 8>\frac{16 h_{w}}{R+4^{1 / \varepsilon}}$, consider a lower $1 / 4^{\mathbb{D}}<\frac{16 h_{e}}{R+4^{1 / \varepsilon}}$ : Let $p(1 / 4)$ denote the probability of an international conłict associated with $f 1 / 4, R ; h_{e} ; h_{w}$;

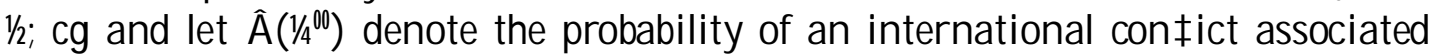

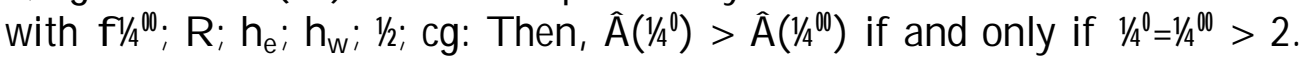

In other terms, the above corollary states that, for every vector of parameters such that there exists two countries in equilibrium, there exists a range of smaller $1 / 45$; such that, for the same $R$ and $h, 1)$ four countries will result in equilibrium, and 2) the probability of international confict will be higher than in the equilibrium with the higher $1 / 4^{36}$ The intuition is straightforward: while a smaller $1 / 4$ reduces the probability of international con $¥$ ict for given borders, the smaller chance that a confict may arise reduces the incentives to form larger countries, and, therefore, increases the number of countries in equilibrium. Therefore, some conficts that would be resolved within domestic borders are now resolved through international confrontation. This indirect exect may oxset the direct exect of a reduction in $1 / 4$ and bring about an increase in the probability of observing an international conłict.

On the other hand, note that, with a lower $1 / 4$ international conłict may be more likely but it will also be more local (in our example, each actual conłict will involve only half of the world rather than the whole world). By the same token, one can note that a reduction in the probability that a confict be solved

\footnotetext{
${ }^{36} \mathrm{~A}$ similar corollary can be derived when the number of countries goes from 2 to 3 , or from 3 to 4.
} 
through open warfare (lower 1 A , by inducing a break-up of countries, may lead to an increase in the probability that an actual war would be observed.

The endogenous reduction in the number and size of countries that may be brought about by a lower probability of potential confict can generate an additional paradoxical exect: a lower $1 / 4$ may induce higher defense per capita in equilibrium. Certainly, defense per capita is increasing in $1 / 4$ for a given con..guration of countries. Therefore, a reduction in the probability $1 / 4$ for given borders, induces a "peace dividend": lower probability of conłict would translate into lower defense per capita in each country. However, a lower $1 / 4$ by inducing a reduction in the equilibrium size of countries, may lead to higher defense per capita in equilibrium. Moreover, even when defense per capita does not increase because of a higher $1 / 4$ any endogenous reduction in size implies a level of defense per capita higher than the level one would observed should borders remain unchanged. In other words, the endogenous link between probability of conłict, defense spending, and size of countries points to reasons why a "peace dividend" may be reduced or completely oxset by a break-up of countries. Formally, we can state the following

\section{Corollary 2}

For any $h_{w} \quad h_{e}$ such that $1 / 4>\frac{16 h_{w}}{R+4^{1 / \varepsilon}}$, consider a lower $1 / 4<\frac{16 h_{e}}{R+4^{4 / \varepsilon}}$ : By Lemma 1, we have that defense per capita at the higher level of $1 / 4$ is given by

$$
d(1 / 4)=\frac{1 / 4 R}{16}
$$

while defense per capita at the lower level of $1 / 4$ is given by

$$
d\left(1 / 4^{m}\right)=\frac{1 / 4^{m} R}{8}
$$

Therefore, we have that $d(1 / 4)>d\left(1 / 4^{\infty}\right)$ if and only if $1 / 4=1 / 4^{\infty}>2$.

Note that, even when $d(1 / 9)>d(1 / 49)$, the peace dividend that is associated with a break-up of countries is given by

$$
P D_{\text {break }}=d(1 / 4) ; \quad d(1 / 4)=\frac{R}{16}\left[1 / 4 ; \quad 2^{1 / 4}\right]
$$

Such "peace dividend" is smaller than the peace dividend that would be observed in the absence of country break-up, that is:

$$
P D_{\text {nobreak }}=\frac{R}{16}\left[\begin{array}{ll}
1 / 4 & 1 / 4
\end{array}\right]
$$




\section{International Law}

Even when wars have no costs ( $c=0$ ), all expenses in defense are pure waste from an eф ciency perspective. A more eф cient solution would be for countries to agree in advance (i.e., before the 'location' of $R$ is known) about a partition of the world in 'spheres of infuence' such that each country would have complete 'control rights' (that is, 'international property rights') over all resources $\mathrm{R}$ that fall within its sphere. In particular, the ..rst best could be achieved by having the four independent regions dividing the circle into four equal segments, and spend nothing on defense. However, in the absence of some form of enforcement, each country has an incentive to deviate from such a solution, invest in its own force, and "invade" its neighbors' spheres of inłuence.

W hile a complete partition can be beyond enforcement, in some 'world orders' a partial partition may be enforceable through some form of "international law", backed by an international enforcement agency and/ or by widely respected social norms. In particular, suppose that the existing international law allows a "secure" area of size $»<1=4$ around each region. Then, only when $R$ falls outside the sphere ("anarchic area") there is actual conłict.

Proposition 1 can then be easily generalized to:

\section{Proposition 2}

For all $0<h_{w} \quad h_{e} ; 1 / 4,0, c, 0,0 \quad 1 / 2 \quad 1$; and $0 \quad \gg \quad 1=4$; in equilibrium we will have

1) Four independent regions ( $N=4$ ) if and only if

$$
\frac{1 / 4}{4}\left(\frac{1}{4} \text { i } \gg\left(\frac{R}{4}+1 / \sqrt{2}\right)<h_{w}\right.
$$

.2) A uni..ed West and two independent countries in the East $(N=3)$ if and only if

$$
\mathrm{h}_{\mathrm{w}}<\frac{1 / 4}{4}\left(\frac{1}{4} \mathrm{i} \gg\right)\left(\frac{\mathrm{R}}{4}+1 / \mathrm{E}\right) \quad \mathrm{h}_{\mathrm{e}}
$$

3) A uni..ed West and a uni..ed East $(N=2)$ if and only if

$$
\frac{1 / 4}{4}\left(\frac{1}{4} \text { i } \gg\right)\left(\frac{R}{4}+1 / \sqrt{2}\right)>h_{e}:
$$

Therefore, an expansion of international control rights reduces the importance of national defense and brings about the formation of smaller countries in equilibrium. However, it is immediate to see that, for the same reasons why a reduction 
in the probability of conłict may lead to more local wars, an expansion in the extent of international property rights (higher $\gg)$, while reducing the level of international "anarchy" and the importance of defense, may lead to a break-up of countries, which may consequently bring about an increase in local conficts and wars.

This result points to the second-best nature of 'improvements' in international law. While a ..rst-best world would emerge from perfectly de..ned international control rights, quite a dixerent outcome may result when one considers extensions of international property rights that do not completely eliminate areas of anarchy and indeterminacy. The post-cold-war world has seen both an increase in the coordinated attempts to enforce international agreements and 'control rights,' and an explosion of local conłicts and separatism. Our analysis suggests a possible explanation for the coexistence of the two phoenomena.

\section{Concluding remarks}

Our stylized model provides insights that seem consistent with recent developments. On the one hand secessions and break-up of countries should go hand in hand with a reduction of international confict, a lower probability of open warfare, and a strengthening of international law. On the other hand, the actual number of international conficts among smaller countries may increase as the result of the break-up of previously larger political unions. We also found that the size of the "peace dividend" is in $¥$ uenced by the process of country fragmentation

These implications of the model seem consistent with the world events that have accompanied the "end of the cold war" . Following the end of a major ideological and geopolitical confrontation between the Soviet Union and the West, we have seen a reduction in the threat of a global war and, possibly, a greater role for international institutions and the rule of international law. At the same time, we have observed a number of secessions not only in the former Soviet Union but also in Eastern Europe and other parts of the world. While some have been peaceful (Czechoslovakia), others have been followed by ethnic and religious conłicts and open warfare (former Y ugoslavia, E ast A frica). Moreover, the decline in the probability of a foreign threat seems to have been accompanied by more vocal separatism and/ or a trend towards more decentralization even in those countries where actual secessions have not taken place.

A Iso, while military spending as percent of GDP has decreased in most countries during the 1990s, the size of the peace dividend seems lower than one may have anticipated given the spectacular collapse of the Soviet Union and the drastic reduction of a threat of a total East-West war. Data from various sources 
dixer because of dixerences in country coverage and de. nition of military expenditure. Data for 90 countries from the International Institute of Strategic Studies (IISS) show a decline in military spending of only 0.4 percent of GDP between 1990 and 1994. WEO data show a decline in military spending of 1.2 percent of GDP between 1990 and 1995. Even within the WEO data set, almost a third of the 130 countries maintained or increased their military spending as a percent of GDP over the period (see Clements, Gupta, and Schix, 1997). In fact, in several countries one has seen substantial increases in defense spending over the period. ${ }^{37}$

Of course, our simple model is not meant to provide a complete and realistic description of the world. In this paper, we have attempted to isolate one factor (international confict) among the numerous factors that can axect the number and size of countries. And we have attempted to study such a factor within the simplest possible framework we could think of. In our analysis, we have abstracted from many dimensions and details of actual international relations and border formation, which should be taken into account when moving from theoretical predictions to the historical record. ${ }^{38}$ However, we believe that our model captures some essential and relevant aspects of the relationship between international conłict and size distribution of political unions. In particular, we think that the following insight is more general than our speci..c model: Incentives to form larger political unions are likely to be higher in a more bellicose, anarchic world, but a reduction in those incentives, by inducing political fragmentation, may bring about its own dose of actual international tensions.

We should emphasize a few possible extensions of our approach. First, we have ignored the role of multiple conficts and alliances, and the related problem of free riding in defense spending by smaller members. To some extent, one can reinterpret the "country" of our model as a group of allied countries, and view our model of country formation as a model of alliance formation. If we reinterpret the model this way, then we can also make sense of the fact that during the cold war the NATO alliance and the Warsaw Pact became tighter alliances. At the apex of the cold war, military alliances with close coordination of defense capabilities did become the norm. In our model a "country" is a political unit in which defense is completely and credibly centralized, and the "returns" from conłict are equally distributed across its citizens. Henceforth, our model in its present form is not designed to address issues of bargaining and free riding amongst allied countries.

\footnotetext{
${ }^{37}$ For instance, in a study by Clements, Gupta and Schix (1997), the ten developing countries with the largest increases in military spending during 1985-92 had an average increase of 2.7 pecentage points of GDP.

${ }^{38}$ In particular, one should consider additional variables, from which we have abstracted in this paper, such as the role of international trade, democratization, etc. For example, on the role of international openness see A lesina, Spolaore and Wacziarg (2000).
} 
While those extensions, in principle, are not outside the scope of our framework, we leave them for future research.

Secondly, we do not explicit study nondemocratic decision rules (nondemocratic country formation and/ or nondemocratic decisions over defense spending, wars, divisions of spoils). One should notice that. within our framework, our results are robust to a large range of decision rules, as individuals within regions and across regions have homogeneous preferences over uni..cation, defense spending, etc. However, the analysis of more complex models in which decision rules could make a crucial dixerence is left for future research. M ore complex political institutions may also give raise to additional reasons to engage in military confict. For instance, Hess and Orphanides $(1995,1997)$ discuss the occurrence of wars chosen strategically by governments in order to signal their competence in military leadership and therefore to boost their chances of being re-elected when faced with domestic problems.

A third extension that we do not pursue here is the introduction of ex-ante income inequality within and across regions, as discussed, for instance, in B olton and Roland (1997). This feature may play an important role in the actual evolution of confict, peace, and the breakup of countries, and may be especially important when we want to interpret the end of the cold war and the breakup of the Soviet Union. More speci..cally, in our analysis we have assumed that the "resource constraint" is not binding when defense is chosen within each country. However, one could extend the model to allow for asymmetries and/or shocks to national income that prevent one or more countries from achieving and/or maintaining the "equilibrium" level of defense, with possible consequences to the overall con..guration of countries. 


\section{Appendix}

\section{A.1. Ideological Conłict}

W hile we have modeled conłict as appropriative/ distributional (conłict over the sharing of an economically valuable "pie"), our model of international conłict between two sovereign countries can be reinterpreted in terms of "ideological confict." For instance, consider two countries with dixerent preferences over a unidimensional ideological issue. As long as each country is able to decide its own policies independently and without axecting its neighbor, no conłict needs to arise. However, it is possible that decisions in one country axect individuals in the other country. For instance, decisions may regard variables that axect the relationship between the two countries (i.e., regulation of pollution with crossborder spillovers), and/ or policies that each country sees as of direct concern to its citizens, even when taking place within the other country's borders (say, human rights, religious policies, etc.). While each country would like to impose its own most preferred type, the equilibrium type will depend on the relative strength of the two countries. To ..x ideas, suppose that there exists a continuum of "types" for some socioeconomic, cultural, religious or otherwise de. ned variable that axects both countries simultaneously. Say, the types are de.ned over the segment $[a ; b]$. Country $j$ prefers type $a$, and obtains a payox equal to $(b ; x) G$ whenever the "type" actually implemented is $x$ such that a $x$ b: A nalogously, country $j$ Oprefers type $b$, and obtains a payox equal to $(x ;$ a $) G$ for $a \quad x \quad b$ : When confict is resolved through the use of the two countries' relative strength (i.e., by using $d_{j}$ and $d_{j}$ ), we have

$$
x^{\not a}=\frac{d_{j}}{d_{j}+d_{j 0}} a+\frac{d_{j} 0}{d_{j}+d_{j} 0} b
$$

and the two countries "payoxs" are given, respectively, by $\frac{d_{j}}{d_{j}+d_{j} 0}\left(b_{i} a\right) G$ and $\frac{d_{j} 0}{d_{j}+d_{j} 0}\left(b_{i} a\right) G$; which is formally equivalent to the above speci..cation for $\left(b_{i}\right.$ a) $G=R$. Therefore, within a preference/ ideological context, $R$ can be interpreted as a measure of the "ideological distance" between the two countries, $\left(b_{i}\right.$ a) times the "relevance" of the issue, $G$.

While we do not pursue this speci..cation explicitly within our framework of endogenous country formation, it is worth noting that our model of confict can be given this alternative interpretation. ${ }^{39}$

\footnotetext{
${ }^{39} \mathrm{~A}$ direct application of this alternative model of conłict to our game of endogenous country formation would require a detailed speci..cation of how dixerent preferences over speci..c issues are distributed across regions and aggregated by uni..ed governments. While this may represent an interesting extension, we leave it for future research.
} 


\section{A.2. Derivations}

\section{Derivation of Lemma 1}

In order to derive Lemma 1, we need to derive the equilibrium defense spending levels for each con..guration of countries.

T wo countries

Denote with $d_{1}^{\mathbb{a}}\left(d_{2}^{\mathbb{a}}\right)$ equilibrium defense spending in country 1 (2) when there are only two countries. The probability of a confict between the two countries is $1 / 42$ : T herefore, the expected total payox in country 1 as a function of defense spending is given by

$$
\frac{1 / 4}{2} \frac{d_{1}}{d_{1}+d_{2}} R ; d_{1}
$$

A nalogously, country 2's expected payou per capita is :

$$
\frac{1 / 4}{2} \frac{d_{2}}{d_{1}+d_{2}} R ; d_{2}
$$

The Nash-equilibrium levels of defense $d_{1}^{\mathbb{\alpha}}$ and $d_{2}^{\mathbb{a}}$ are de.ned as

$$
\begin{aligned}
& d_{1}^{\mathrm{\alpha}}=\operatorname{argmax} \frac{1 / 4}{2} \frac{R d_{1}}{d_{1}+d_{2}^{\alpha}} ; \quad d_{1} \\
& d_{2}^{\mathrm{\alpha}}=\operatorname{argmax} \frac{1 / 4}{2} \frac{R d_{2}}{d_{1}^{\alpha}+d_{2}} ; \quad d_{2}
\end{aligned}
$$

which imply the ..rst order conditions

$$
\frac{d_{2}^{\alpha}}{\left(d_{1}^{\alpha}+d_{2}^{\alpha}\right)^{2}}=\frac{d_{1}^{\alpha}}{\left(d_{1}^{\alpha}+d_{2}^{\alpha}\right)^{2}}=\frac{2}{1 / R}
$$

whose solution is

$$
d_{1}^{\alpha}=d_{2}^{\alpha}=\frac{1 / R}{8}
$$

As each country has a total population of size equal to 2 , defense spending per capita in each country is 


$$
\frac{d_{1}^{\alpha}}{2}=\frac{d_{2}^{\alpha}}{2}=\frac{1 / R}{16}
$$

In a two-player game, a unique Nash equilibrium is also coalition-proof.

Three countries

When a country formed by two regions (say, country 1 ) coexists with two independent regions (say, country 2 and country 3), the Nash-equilibrium levels of defense equilibrium defense $d_{1}^{\alpha}, d_{2}^{\alpha}$ and $d_{3}^{\alpha}$ are given by

$$
\begin{aligned}
& d_{1}^{\alpha}=\arg \max _{d_{1}} \frac{1 / R}{4}\left[\frac{d_{1}}{d_{1}+d_{2}^{\alpha}}+\frac{d_{1}}{d_{1}+d_{3}^{\alpha}}\right] ; \quad d_{1} \\
& d_{2}^{\alpha}=\arg \max _{d_{2}} \frac{1 / R}{4}\left[\frac{d_{2}}{d_{1}^{\alpha}+d_{2}}+\frac{d_{2}}{d_{2}+d_{3}^{\alpha}}\right] ; \quad d_{2} \\
& d_{3}^{\alpha}=\arg \max _{d_{3}} \frac{1 / R}{4}\left[\frac{d_{3}}{d_{1}^{\alpha}+d_{3}}+\frac{d_{3}}{d_{2}^{\alpha}+d_{3}}\right] ; \quad d_{3}
\end{aligned}
$$

whose solution is:

$$
d_{1}^{\alpha}=d_{2}^{\alpha}=d_{3}^{\alpha}=\frac{1 / R}{8}
$$

As country one has a population of size equal to 2, while countries 2 and 3 have population of sizes 2 and 3 each, we have level of defense per capita equal to $\frac{1 / R}{16}$ in country 1 , and equal to $\frac{1 / R}{8}$ in countries 2 and 3 .

We also need to show that the above Nash equilibrium (A.9) is also coalitionproof. To verify that, note that, given any set of defense spending by any proper subset of countries, the game induced on the remaining countries has a unique Nash equilibrium.

Speci..cally:

a) given the level of defense spending in country $1\left(d_{1}\right)$, the game induced on countries 2 and 3 has a unique Nash equilibrium, given by

$$
d_{2}^{\mathrm{a}}\left(d_{1}\right)=\arg \max _{d_{2}} \frac{1 / R}{4}\left[\frac{d_{2}}{d_{1}+d_{2}}+\frac{d_{2}}{d_{2}+d_{3}^{d}\left(d_{1}\right)}\right] ; \quad d_{2}
$$




$$
d_{3}^{\mathrm{a}}\left(\mathrm{d}_{1}\right)=\arg \max _{\mathrm{d}_{3}} \frac{1 / R}{4}\left[\frac{\mathrm{d}_{3}}{\mathrm{~d}_{1}+\mathrm{d}_{3}}+\frac{\mathrm{d}_{3}}{\mathrm{~d}_{2}^{\mathrm{a}}\left(\mathrm{d}_{1}\right)+\mathrm{d}_{3}}\right] \mathrm{i} \mathrm{d}_{3}
$$

b) given the level of defense spending in country $2\left(d_{2}\right)$, the game induced on countries 1 and 3 has a unique Nash equilibrium characterized by the solution of the following two ..rst-order conditions:

$$
\begin{aligned}
& d_{1}^{\mathrm{a}}\left(d_{2}\right)=\arg \max _{d_{1}} \frac{1 / R}{4}\left[\frac{d_{1}}{d_{1}+d_{2}}+\frac{d_{1}}{d_{1}+d_{3}^{\mathfrak{a}}\left(d_{2}\right)}\right] ; \quad d_{1} \\
& d_{3}^{\mathfrak{a}}\left(d_{2}\right)=\arg \max _{d_{3}} \frac{1 / R}{4}\left[\frac{d_{3}}{d_{1}^{\mathbb{a}}\left(d_{2}\right)+d_{3}}+\frac{d_{3}}{d_{2}+d_{3}}\right] ; \quad d_{3}
\end{aligned}
$$

A nalogously, there exists a unique Nash equilibrium for the game induced on countries 1 and 2, given the actions of country 3 .

Since the game induced on the remaining countries has a unique Nash equilibrium for any set of choices of defense spending by any proper subset of countries, we have that, by de..nition, the set of coalition-proof equilibria coincide with the Pareto ed cient frontier of the set of Nash equilibria, ${ }^{40}$ which, in our case, is given by the unique $N$ ash equilibrium as characterized in equation (A.9).

\section{Four countries}

When four independent countries (say, countries 1,2,3, and 4), each of size equal to 1, coexist, the Nash equilibrium is given by

$$
\begin{aligned}
& d_{1}^{\alpha}=\arg \max _{d_{1}} \frac{1 / R}{4}\left[\frac{d_{1}}{d_{1}+d_{2}^{\alpha}}+\frac{d_{1}}{d_{1}+d_{4}^{\alpha}}\right] ; \quad d_{1} g \\
& d_{2}^{\alpha}=\arg \max _{d_{2}} \frac{1 / R}{4}\left[\frac{d_{2}}{d_{1}^{\alpha}+d_{2}}+\frac{d_{2}}{d_{2}+d_{3}^{\alpha}}\right] ; \quad d_{2} g \\
& d_{3}^{\alpha}=\arg \max _{d_{3}} \frac{1 / R}{4}\left[\frac{d_{3}}{d_{2}^{\alpha}+d_{3}}+\frac{d_{3}}{d_{3}+d_{4}^{\alpha}}\right] ; \quad d_{3} g \\
& d_{4}^{\alpha}=\arg \max _{d_{4}} \frac{1 / R}{4}\left[\frac{d_{4}}{d_{1}^{\alpha}+d_{4}}+\frac{d_{4}}{d_{3}^{\alpha}+d_{4}}\right] ; \quad d_{4} g
\end{aligned}
$$

\footnotetext{
${ }^{40}$ See B ernheim, Peleg, and Whinston (1987), p. 8.
} 
whose solution is

$$
d_{1}^{\alpha}=d_{2}^{\alpha}=d_{3}^{\alpha}=d_{4}^{\alpha}=\frac{1 / R}{8}
$$

which implies defense spending per capita equal to $\frac{1 / R}{8}$ in each country.

As in the case of three countries, it is straightforward to show that, given any set of defense spending by any proper subset of countries, the game induced on the remaining countries has a unique Nash equilibrium. Therefore, the levels of defense derived in equation (A.17) characterize the unique coalition-proof equilibrium defense levels.

The above analysis shows that, for any possible con..guration of countries, in equilibrium we have that a country formed by two regions has defense per capita equal to $\frac{1 / R}{16}$, while a country formed by one region has defense per capita equal to $\frac{1 / R}{8}: Q E D$

\section{Derivation of Lemma 2}

The expected returns from con $¥$ ict (including potential con $¥ i c t$ that is resolved within a country's borders) can be calculated as follows:

W ith two country, individuals in country 1 expect:

$$
\frac{1}{2}\left[\frac{1 / R}{4}+\frac{1 / R}{2} \frac{d_{1}^{\mathrm{x}}}{d_{1}^{\mathrm{a}}+\mathrm{d}_{2}^{\mathrm{\alpha}}}\right]=\frac{1 / R}{4}
$$

The same returns are expected by individuals in country 2 .

W ith three countries, individuals in the larger country (say, country 1) expect:

$$
\frac{1}{2}\left[\frac{1 / R}{4}+\frac{1 / R}{4} \frac{d_{1}^{\alpha}}{d_{1}^{\alpha}+d_{2}^{\alpha}}+\frac{1 / R}{4} \frac{d_{1}^{\alpha}}{d_{1}^{\alpha}+d_{3}^{\alpha}}\right]=\frac{1 / R}{4}
$$

while the two smaller countries (say, countries 2 and 3 ) expect

$$
\frac{1 / R}{4} \frac{d_{2}^{\alpha}}{d_{1}^{\alpha}+d_{2}^{\alpha}}+\frac{1 / R}{4} \frac{d_{2}^{\alpha}}{d_{2}^{\alpha}+d_{3}^{\alpha}}=\frac{1 / R}{4} \frac{d_{3}^{\alpha}}{d_{1}^{\alpha}+d_{3}^{\alpha}}+\frac{1 / R}{4} \frac{d_{3}^{\alpha}}{d_{2}^{\alpha}+d_{3}^{\alpha}}=\frac{1 / R}{4}
$$

F inally, analogous calculations show that, with four countries, each will expect $\frac{1 / R}{4}$ : 
The war costs are given by $\frac{1 / 4^{2} / \varepsilon}{2}$ in a country formed by two regions (i.e., $s_{i}=2$ ) and $\frac{1 / 2}{2} /\left[/\left[\right.\right.$ in a country formed by one region (i.e., $s_{i}=1$ ). Therefore, Lemma 2 holds.

\section{Derivation of Lemma 3}

As shown above, the absolute level of defense in equilibrium is always $\frac{1 / R}{8}$. Therefore, the expected probability of winning a con $\neq$ ict is $1 / 2$ for each country. In a country formed by two regions, expected conłict returns per capita net of expected war costs are given by

$$
\frac{1 / R}{4} \frac{1}{2}+\frac{1 / 4}{2}\left[\frac{R}{2} ; \quad 1 / \frac{C}{2}\right]=\frac{1 / 4 R ; 1 / \sqrt{2})}{4}
$$

where the ..rst term indicates the "peaceful" division of $\mathrm{R}$ within the country, the second term indicates the expected payou from confict resolution, and the third term refers to the costs of war.

By contrast, net payoo in a country formed by one region is

$$
\frac{1 / 4}{2}\left[\frac{1}{2} R ; 1 /[\bar{\varepsilon}]=\frac{\left.1 / 4 R ; 2^{1 / \varepsilon}\right)}{4}\right.
$$

Individual utility in a country formed by two regions is

$$
U_{\text {uni }}=y i \frac{1 / R}{16}+\frac{1 / 4 R ; 1 / \varepsilon)}{4} ; h_{k}
$$

while in a country formed by one region individual utility is given by

$$
\mathrm{U}_{\text {ind }}=\mathrm{yi}_{\mathrm{i}} \frac{1 / \mathrm{R}}{8}+\frac{\left.1 / 4 \mathrm{R} \mathrm{i}^{1 / 1 / \varepsilon}\right)}{4}
$$

therefore, uni..cation is (strictly) preferred to independence if and only if

$$
\frac{1 / 4}{4}\left(\frac{R}{4}+1 / \mathfrak{L}\right)>h_{k}
$$

QED.

Derivation of Proposition 1

Proposition 1 is an immediate implication of Lemma 3. 
It is immediate to see that Proposition 1 characterizes a Nash equilibrium. M oreover, for any other Nash equilibrium there will be a group of individuals who will be strictly better ox by deviating and moving to the equilibrium characterized in Proposition 1.

First, consider the case $\frac{1 / 4}{4}\left(\frac{R}{4}+1 / \mathfrak{L}\right)<h_{w}$. In this case, voting for independence is a dominant strategy for each individual. For any equilibrium in which a majority has voted for uni..cation, there exists a coalition of individuals (in fact, everybody) who would be better ox by switching to independence. Hence, independence for all regions is the only outcome that can be sustained as a Coalition-proof Nash equilibrium.

When $h_{w}<\frac{1 / 4}{4}\left(\frac{R}{4}+1 / \bar{L}\right)<h_{e}$; any outcome in which the E ast is uni..ed would be upset by a majority (in fact, all) Eastern individuals, who are better ox when the two Eastern regions are independent. On the other hand, voting for uni..cation is the dominant strategy in the West. where.

When $\frac{1 / 4}{4}\left(\frac{R}{4}+1 / \mathfrak{L}\right)>h_{e} ;$ voting for uni..cation is the dominant strategy every-

\section{QED}

\section{A.3 Regions with $M$ voters}

For simplicity, in the text we have assumed that the number of voters in each region is equal to one. It is easy to show that our results do not depend on that simpli..cation. As governments maximize the sum of utilities, payous in stage two and three are just multiplied by either $M$ or $2 M$, and give the same equilibrium outcomes. In stage one, all individuals in each region have the same utility function. In particular, Lemma 3 can be reformulated as follows:

\section{Lemma 3'}

Given heterogeneity cost $h_{k}(k=w ; e)$, and given the equilibrium payoxs associated with all possible con..gurations of countries (i.e., with all terminal twostage subgames), individuals will (strictly) prefer to live in a two-region country rather than in an independent region if and only if

$$
\frac{1 / 4}{4 M}\left(\frac{R}{4}+1 / \varepsilon\right)>h_{k}
$$

When we consider coalition-proof equilibria, we have that all voters within a region will coordinate on their non weakly dominated strategy (uni..cation if 
$\frac{1 / 4}{4 M}\left(\frac{R}{4}+1 / \varepsilon\right)>h_{k}$, independence if $\left.\frac{1 / 4}{4 M}\left(\frac{R}{4}+1 / \sqrt{2}\right) \quad h_{k}\right)$. Therefore, it is immediate to show that Proposition 1 can be reformulated as follows:

Proposition 1'

For all $0<h_{w} \quad h_{e} ; 1 / 4,0, c, 0$ and $0 \quad \frac{1}{2} \quad 1$; and $M, 1$ in equilibrium we will have

1) Four independent regions ( $N=4$ ) if and only if

$$
\frac{1 / 4}{4 M}\left(\frac{R}{4}+1 / \bar{L}\right) \quad h_{w}:
$$

2) A uni..ed W est and two independent countries in the East ( $N=3$ ) if and only if

$$
\mathrm{h}_{\mathrm{w}}<\frac{1 / 4}{4 \mathrm{M}}\left(\frac{\mathrm{R}}{4}+1 / \mathrm{E}\right) \quad \mathrm{h}_{\mathrm{e}}:
$$

3) A uni..ed West and a uni..ed East ( $N=2$ ) if and only if

$$
\frac{1 / 4}{4 M}\left(\frac{R}{4}+1 / \sqrt{2}\right)>h_{e}:
$$

The comparative-statics of changes in $\mathrm{M}$ will depend on whether any other parameter (e.g., $R ; h_{e} ; h_{w}$ ) is a function of $M$. 


\section{REFERENCES}

Alesina, A., R. Perotti and E. Spolaore (1995), "Together or Separately? Issues on the Costs and Bene..ts of Political and Fiscal Unions," European Economic Review, April.

A lesina, A., and E. Spolaore (1997), "On the Number and Size of Nations," Quarterly J ournal of E conomics, November.

Alesina, A. and E. Spolaore (2000), "Confict, Defense Spending, and the Number of Nations," unpublished.

A lesina, A., E. Spolaore and R. Wacziarg (2000), "E conomic Integration and Political Disintegration," American Economic Review, December.

A umann, R.J . (1959), "A cceptable Points in General Cooperative n-person," in Contributions to the Theory of Games IV, P rinceton University Press.

A umann, R .J . (1990), "Nash Equilibria A re Not Self-Enforcing," in E conomic Decision-Making: Games, Econometrics and Optimisation, edited by J.J . Gabsewicz, J .-F. Richard and L.A. Wolsey, Elsevier Science Publishers.

B ernheim, D., D. Peleg and M. W hinston (1987), "C oalition-P roof Nash Equilibria. I: Concepts," J ournal of E conomic Theory. 42: 13-22.

B olton, P. and G. Roland (1987), "The Breakup of Nations: A Political E conomy A nalysis," Quarterly J ournal of E conomics, November.

Bolton, P., G. Roland and E. Spolaore (1996), "Economic Theories of the B reak-up and Integration of Nations," European Economic Review, A pril.

B oulding, K.E. (1962), Conłict and Defense: A General Theory, Harper, New York.

B rown, M.E., O.R. Cote, J r., S. M. Lynn-J ones and S.E. M iller (eds.), Theories of War and Peace, MIT Press.

Casella, A., and J. Feinstein (1990), "Public Goods in Trade: On the Formation of Markets and Political J urisdictions," NBER Working Paper No. 3554, December.

Clemens, B. S. Gupta and J. Schiø (1997), "What Happened to the Peace Dividend?" Finance \& Development, March.

Dahl, R. A . and E. R. Tufte (1973), Size and Democracy, Stanford University Press. 
Farrell, J . (1988) "Communication, Coordination, and Nash Equilibrium," Economics Letters, 27: 209-214.

Findlay, R ., (1996), "Towards a M odel of Territorial Expansion and the Limits of Empire," in The Political Economy of Con $¥$ ict and Appropriation, edited by Michelle R. Gar..nkel and Stergios Skaperdas, Cambridge University Press.

Friedman, D. (1977), "A Theory of the Size and Shape of Nations," J ournal of Political Economy, 85 (1).

Fudenberg, D. and J . Tirole (1991), Game Theory, MIT Press.

Gar..nkel, M .R. (1994), "Domestic Politics and International Conłict," American Economic Review, December.

Grossman, H.I., (1991), "A General Equilibrium Model of Insurrections," American Economic Review, September.

Grossman, H.I., (2000), "The State: Agent or Proprietor?", Economics of Governance.

Grossman, H.I., and M. Kim (1995) "Swords or Plowshares? A Theory of the Security of Claims to Property," J ournal of Political Economy, December, 103.

Harsanyi, J . and R. Selten (1988), A General Theory of Equilibrium Selection in Games, MIT Press.

Hartley, K., and T. Sandler, (1995), Handbook of Defense E conomics, NorthHolland: A msterdam.

Hess, G.D. and A. Orphanides (1995), "War Politics: An Economic, Rational Voter Framework," American Economi Review, September, 85(4): 828-846.

Hess, G.D. and A. Orphanides (1997), "War and Democracy," unpublished.

Hirshleifer, J . (1989), "Conłict and Rent-Seeking Success Functions: Ratio versus Dixerence M odels of Relative Success," Public Choice, November.

Hirshleifer, J . (1991), "The Technology of Conłict as an Economic Activity," American Economic Review, May.

Hirshleifer, J. (1995), "A narchy and Its Breakdown," J ournal of Political Economy, Vol. 103, February.

Hobsbawn, E.J . (1994), T he Age of Extremes, Vintage Books, New York. 
J ervis, R. (1978), "Cooperation under the Security Dilemma," W orld Politics, 30: $167-214$.

Olson, M., and R. Zeckhauser (1966), "An E conomic theory of Alliances," Review of Economics and Statistics, 48, 266-79.

Rubinstein, A. (1980), "Strong Perfect Equilibria in Supergames," International J ournal of Game Theory, 9: 1-12.

Sandler, T., and K. Hartley (1995), The Economics of Defense, Cambridge University Press, New York.

Schelling, T.C. (1960), The Strategy of Conłict, Harvard University Press, Cambridge (MA).

Schelling, T.C. (1966), Arms and Inłuence, Yale University P ress.

Skaperdas, S. (1992), "Cooperation, Conłict and Power in the Absence of Property Rights," American E conomic Review, September.

Tullock, G. (1974), The Social Dilemma: The Economics of War and Revolution, University P ub., B lacksburg (VA).

Tullock, G. (1980), "E $₫$ cient Rent Seeking," in Toward a Theory of the RentSeeking Society, edited by J.M. Buchanan, R.D. Tollison, and G. Tullock, Texas $A \& M$ University Press, College Station.

Van Evera, S. (1998), "Oxense, Defense, and the Causes of War," International Security, 4: 5-43.

Wei, Shang-J in (1992), "To Divide or to United: A Theory in Secessions," unpublished. 